\title{
LAPTM4B gene copy number gain is associated with inferior response to anthracycline-based chemotherapy in hormone receptor negative breast carcinomas
}

Rusz, Orsolya; Papp, Orsolya; Vizkeleti, Laura; Molnar, Bela Akos; Bende, Kristof Csaba; Lotz, Gabor; Acs, Balazs; Kahan, Zsuzsanna; Szekely, Tamas; Bathori, Agnes

Total number of authors:

14

Published in:

Cancer Chemotherapy and Pharmacology

Link to article, DOI:

$10.1007 / \mathrm{s} 00280-018-3602-z$

Publication date:

2018

Document Version

Publisher's PDF, also known as Version of record

Link back to DTU Orbit

Citation (APA):

Rusz, O., Papp, O., Vizkeleti, L., Molnar, B. A., Bende, K. C., Lotz, G., Acs, B., Kahan, Z., Szekely, T., Bathori, A., Szundi, C., Kulka, J., Szallasi, Z. I., \& Tokes, A-M. (2018). LAPTM4B gene copy number gain is associated with inferior response to anthracycline-based chemotherapy in hormone receptor negative breast carcinomas. Cancer Chemotherapy and Pharmacology, 82, 139-147. https://doi.org/10.1007/s00280-018-3602-z

\section{General rights}

Copyright and moral rights for the publications made accessible in the public portal are retained by the authors and/or other copyright owners and it is a condition of accessing publications that users recognise and abide by the legal requirements associated with these rights.

- Users may download and print one copy of any publication from the public portal for the purpose of private study or research.

- You may not further distribute the material or use it for any profit-making activity or commercial gain

- You may freely distribute the URL identifying the publication in the public portal 


\title{
LAPTM4B gene copy number gain is associated with inferior response to anthracycline-based chemotherapy in hormone receptor negative breast carcinomas
}

\author{
Orsolya Rusz ${ }^{1}$ - Orsolya Papp ${ }^{2}$ - Laura Vízkeleti ${ }^{2,3}$ - Béla Ákos Molnár ${ }^{4} \cdot$ Kristóf Csaba Bende $^{2}$ - Gábor Lotz ${ }^{2}$. \\ Balázs Ács ${ }^{2}$ - Zsuzsanna Kahán ${ }^{1}$. Tamás Székely ${ }^{2}$. Ágnes Báthori ${ }^{5} \cdot$ Csilla Szundi $^{2}$ · Janina Kulka ${ }^{2}$. \\ Zoltán Szállási ${ }^{2,3,6,7}$. Anna-Mária Tökés ${ }^{2}$
}

Received: 20 February 2018 / Accepted: 12 May 2018 / Published online: 16 May 2018

(c) Springer-Verlag GmbH Germany, part of Springer Nature 2018

\begin{abstract}
Purpose To determine the associations between lysosomal-associated transmembrane protein $4 \mathrm{~b}$ (LAPTM4B) gene copy number and response to different chemotherapy regimens in hormone receptor negative (HR-) primary breast carcinomas. Patients and methods Two cohorts were analyzed: (1) 69 core biopsies from HR-breast carcinomas treated with neoadjuvant chemotherapy (anthracycline based in $72.5 \%$ of patients and non-anthracycline based in $27.5 \%$ of patients). (2) Tissue microarray (TMA) of 74 HR-breast carcinomas treated with adjuvant therapy (77.0\% of the patients received anthracycline, $17.6 \%$ of the patients non-anthracycline-based therapy, and in 5.4\% of the cases, no treatment data are available). Interphase FISH technique was applied on pretreatment core biopsies (cohort I) and on TMAs (cohort II) using custom-made duallabelled FISH probes (LAPTM4B/CEN8q FISH probe Abnova Corp.).

Results In the neoadjuvant cohort in the anthracycline-treated group, we observed a significant difference $(p=0.029)$ of average $L A P T M 4 B$ copy number between the non-responder and pathological complete responder groups $(4.1 \pm 1.1 \mathrm{vs}$. $2.6 \pm 0.1)$. In the adjuvant setting, the anthracycline-treated group of metastatic breast carcinomas was characterized by higher $L A P T M 4 B$ copy number comparing to the non-metastatic ones $(p=0.046)$. In contrast, in the non-anthracycline-treated group of patients, we did not find any $L A P T M 4 B$ gene copy number differences between responder vs. non-responder groups or between metastatic vs. non-metastatic groups.

Conclusion Our results confirm the possible role of the $L A P T M 4 B$ gene in anthracycline resistance in HR- breast cancer. Analyzing $L A P T M 4 B$ copy number pattern may support future treatment decision.
\end{abstract}

Keywords Breast carcinomas $\cdot$ LAPTM4B $\cdot$ Anthracycline-based chemotherapy $\cdot$ FISH

\section{Introduction}

In the 1990s, chemotherapy regimens containing anthracyclines largely replaced the previous regimen of cyclophosphamide, methotrexate, and 5-fluorouracyl (CMF) for the

Orsolya Rusz and Orsolya Papp have contributed equally.

Electronic supplementary material The online version of this article (https://doi.org/10.1007/s00280-018-3602-z) contains supplementary material, which is available to authorized users.

Anna-Mária Tőkés

tokesa1972@yahoo.co.uk; ta@korb2.sote.hu

Extended author information available on the last page of the article treatment of breast cancer. Subsequently, anthracyclines (doxorubicin and epirubicin) became the most widely used chemotherapeutic agents for breast cancer given as either adjuvant or neoadjuvant therapy $[1,2]$. However, in the era of personalized therapy, clinical decision could be significantly optimized by a robust and reliable biomarker predicting response to this therapy.

Several potential response predictors for anthracyclines, such as increased topoisomerase-II-alpha levels, were proposed, but none of those has reached or passed the stage of large-scale independent clinical validation with the desired predictive potential [3, 4].

Using an integrative genomics approach, Li et al. [5] identified a functionally validated predictor of anthracycline treatment efficacy. Amplification of chromosomal region 
8 q22 was significantly associated with treatment resistance. Expression levels of one of the genes contained in that region, the lysosomal-associated transmembrane protein $4 \mathrm{~b}$ (LAPTM4B), could be linked to altering the intracellular distribution of anthracycline in experimental circumstances. Anthracyclines likely enter the cells via simple diffusion [6], where they bind to proteasomes and by an ATP-dependent nuclear pore-mediated mechanism get transported into the nuclei [7]. Both doxorubicin and epirubicin are weak bases; they can accumulate in acidic intracellular compartments, such as the lysosomes. Several studies reported that resistant cancer cells are able to accumulate significantly more anthracyclines in cytoplasmic organelles, resulting in reduced nuclear drug accumulation and decreased cytotoxicity [8], but the potential molecular regulation of the drug sequestration in acid lysosomes has been unclear. In the previous experiments, the knockdown of LAPTM4B significantly decreased the ability of lysosomes to retain doxorubicin [5]. According to other results, the preservation of lysosome membrane integrity by LAPTM4B also prevents cathepsin release and the following caspase-mediated apoptosis, which was detectable after doxorubicin but not taxol exposure [9].

In the current study, we investigated whether we could potentially convert the initial observations of $\mathrm{Li}$ et al. [5] into a diagnostic test that is widely available in the diagnostic setting: FISH-based copy number analysis. To achieve this, first, we needed to determine whether the LAPTM4B/ CEN8q ratio or the average copy number of LAPTM4B/ cell was more robustly informative of treatment response. The ultimate aim of the study was to determine whether the presence of extra copy of LAPTM4B gene had negative predictive value to anthracycline-based treatment in patients with hormone receptor negative (HR-) breast carcinomas.

\section{Patients and methods}

\section{Study population}

A total of $143 \mathrm{HR}$ - breast carcinoma cases were enrolled in this study and were analyzed in two different cohorts. The study was ethically approved by the Semmelweis University Institutional Review Board (SE-TUKEB 120/2013).

The first cohort included 69 core biopsies of HR- (64 TNBC and 5 HER2+) primary breast carcinoma cases diagnosed between 2004 and 2016, who received at least two cycles of neoadjuvant chemotherapy, and then underwent surgery. Patients were eligible for neoadjuvant therapy if they had histologically confirmed invasive breast cancer and imaging examinations ruled out distant metastases.

Fifty out of sixty-nine (72.5\%) patients were treated with anthracycline-based neoadjuvant chemotherapy (mainly in combination with taxane), whereas 19 patients (27.5\%) represented the control arm receiving non-anthracycline-based (mostly platinum in combination with taxane) chemotherapy. The clinicopathological data are presented in Table 1 . The detailed treatment data are presented in supplementary Table 1.

The degree of response to therapy was categorized following Pinder et al. [10]. Complete pathological response (pCR) either (1) no residual carcinoma in breast and lymph nodes or (2) no residual invasive tumor, but DCIS present in breast and the absence of any residual invasive tumor in the lymph nodes. Partial response to therapy (pPR) either (1) minimal residual disease/near total effect (e.g., $<10 \%$ of tumor remaining) or (2) evidence of response to therapy but with $10-50 \%$ of tumor remaining or (3) $>50 \%$ of tumor cellularity remains evident, when compared with the previous core biopsy sample, although some features of response to therapy present. No evidence of response to therapy (pNR).

The second cohort included 74 formalin-fixed paraffin-embedded (FFPE) samples of surgically removed HR- breast carcinomas (39 TNBC, 27 HER2+, and 8 with no reliable HER2 data). Patients in this cohort were treated

Table 1 Clinicopathological characteristics of the study group treated with neoadjuvant chemotherapy

\begin{tabular}{lc}
\hline Parameter & No. of patients $(N=69)$ \\
\hline Mean age (years) & 50 (range: $26-79)$ \\
IHC-based molecular types & \\
TNBC & $64(92.8 \%)$ \\
HR-, HER2+ & $5(7.2 \%)$ \\
Clinical tumor stage & \\
Primary tumor & \\
T1 & $2(2.9 \%)$ \\
T2 & $42(60.9 \%)$ \\
T3 & $12(17.4 \%)$ \\
T4 & $13(18.8 \%)$ \\
Regional lymph node & \\
N0 & $25(36.2 \%)$ \\
N1 & $19(27.5 \%)$ \\
N2 & $19(27.5 \%)$ \\
N3 & $6(8.8 \%)$ \\
Therapy & \\
Anthracycline-based & $50(72.5 \%)$ \\
Non-anthracycline-based & $19(27.5 \%)$ \\
Pathological response to neoadjuvant therapy & \\
pCR & $26(37.7 \%)$ \\
pPR & $38(55.1 \%)$ \\
pPRi & $6(15.78 \%)$ \\
pPRii & $13(34.21 \%)$ \\
pPRiii & $19(50 \%)$ \\
\hline & $5(7.2 \%)$ \\
\hline
\end{tabular}


with chemotherapy in adjuvant setting between 1999 and 2006. Of these patients, 57/74 (77.0\%) received anthracycline-based (22.8\% in combination with taxane) and $13 / 74(17.6 \%)$ received non-anthracycline-based therapies (as control arm), mainly CMF regimens. In 4/74 (5.4\%) cases, no reliable treatment data were available. The clinicopathological data are presented in Table 2. The detailed treatment data are presented in supplementary Table 2 . In the adjuvant cohort, distant metastasis-free survival (DMFS) was assessed and defined as the time elapsed between the first diagnosis of primary breast carcinoma and the date of appearance of any distant metastasis. The occurrence or absence of distant metastasis was considered as an indirect surrogate marker for response to different chemotherapy regimens.

Follow-up data collection for both cohorts ended in December 2016.

Table 2 Clinicopathological characteristics of the study group treated with adjuvant chemotherapy

\begin{tabular}{lc}
\hline Parameter & No. of patients $(N=74)$ \\
\hline Mean age (year) & 52 (range: 32-81) \\
IHC-based molecular types & $39(52.7 \%)$ \\
TNBC & $27(36.5 \%)$ \\
HR-, HER2+ & $8(10.8 \%)$ \\
HR-, HER2 n.a. & \\
Pathologic tumor stage & \\
Primary tumor & $19(25.6 \%)$ \\
pT1 & $37(50.0 \%)$ \\
pT2 & $9(12.2 \%)$ \\
pT3 & $5(6.8 \%)$ \\
pT4 & $4(5.4 \%)$ \\
Unknown & \\
Regional lymph node & $19(25.6 \%)$ \\
pN0 & $21(28.4 \%)$ \\
pN1 & $17(23.0 \%)$ \\
pN2 & $4(5.4 \%)$ \\
pN3 & $13(17.6 \%)$ \\
Unknown & \\
Distant metastases & $30(40.5 \%)$ \\
Yes & $44(59.5 \%)$ \\
No & \\
Therapy & $57(77.0 \%)$ \\
Anthracycline-based & $13(17.6 \%)$ \\
Unknown & $4(5.4 \%)$ \\
\hline &
\end{tabular}

\section{Evaluation of LAPTM4B copy number using FISH technique}

Interphase FISH analysis was used to evaluate the copy number status of $L A P T M 4 B$ gene.

$5 \mu \mathrm{m}$-thick FFPE tissue sections were mounted onto Superfrost Plus positively charged slides, and deparaffinized and rehydrated in distilled water. For antigen retrieval, sections were incubated in citric acid-based antigen unmasking solution (Vector Laboratories, Inc. Burlingame, CA, USA) at $95{ }^{\circ} \mathrm{C}$ for $20 \mathrm{~min}$. Cell lysis was established by incubating the sections in Triton X-100 (AppliChem GmbH, Ottoweg 4, 64291 Darmstadt, Germany) -SSC solution at $65^{\circ} \mathrm{C}$ for $30 \mathrm{~min}$. Sections were then subjected to digestion in pepsin solution, for $12 \mathrm{~min}$ at $37{ }^{\circ} \mathrm{C}$, and then washed twice in SSC for 5 min. ZytoLight ${ }^{\circledR}$ FISH-Tissue Implementation Kit (ZytoVision GmbH, Bremerhaven, Germany) was used in prehybridizational steps. Sections were air-dried prior to denaturation at $73{ }^{\circ} \mathrm{C}$ for $10 \mathrm{~min}$. Hybridization was performed using $4 \mu \mathrm{l}$ of custom-made, Texas Red/FITC duallabelled LAPTM4B/CEN8q FISH probes (Abnova Corp., Taoyuan City, Taiwan) per slide at $37^{\circ} \mathrm{C}$ for $16-18 \mathrm{~h}$ in an automated hybridization chamber (ZYTOMED Systems $\mathrm{GmbH}$ Berlin, Germany). Slides were then immersed in wash buffer SSC for $30 \mathrm{~min}$ at $45^{\circ} \mathrm{C}$, rinsed in water for $10 \mathrm{~min}$, air-dried. Cell nuclei were counterstained with DAPI in antifade solution (Vector Laboratories, Inc. Burlingame, CA, 94010, USA).

The Leica DM RXA fluorescent microscope equipped with Leica DFC 365FX high-performance CCD camera (Leica Microsystems GmbH, Wetzlar, Germany) and with DAPI long-pass, FITC, and Texas Red filters was used to evaluate the hybridization results.

Areas with well-separated cell nuclei and overall good hybridization signals were selected for analysis. Minimum two FISH images per case were digitally captured at $63 \mathrm{x}$ magnification. For each case, red (LAPTM4B) and green (CEN8 centromeric region) fluorescent signals were counted separately in at least 50 non-overlapping interphase nuclei. Based on these data, the following parameters were calculated: average $L A P T M 4 B$ copy number/cell, average CEN8q copy number/cell, $L A P T M 4 B / C E N 8 q$ ratio, average $L A P T M 4 B$ copy number/cell in amplified cell population, and percentage of polysomic or amplified cells.

\section{Statistical analysis}

SPSS 23.0 (SPSS Inc., Chicago, IL, USA) was used for statistical analysis. The Shapiro-Wilk test was applied to control the normality of data, and Leven's test was used to control the equality of variances. Non-parametric tests were applied for statistical analyses. Receiver-operating characteristic (ROC) curve analysis was used to determine the optimal 
cut-off value of $L A P T M 4 B$ copy number used in survival tests. Fisher's exact, Kruskal-Wallis, and Mann-Whitney-Wilcoxon tests were used to compare the $L A P T M 4 B$ copy number to the clinical-pathological data of the primary tumors, including therapy response in neoadjuvant cohort and distant metastasis formation in adjuvant cohort as end point. The Kaplan-Meier, log-rank, and Cox regression tests were used for survival analysis (DMFS-distant metastasisfree survival). The Cox model included the known breast carcinoma prognostic factors such as age at the initial diagnosis, $\mathrm{pT}$, and $\mathrm{pN}$ status beside $L A P T M 4 B$ copy number category. A $p$ value of less than 0.05 was considered statistically significant.

\section{Results}

In the first cohort, the mean age of patients was 50 years (range: $26-79$ years); all cases had invasive carcinoma of no special type. Based on the subtypes, 64/69 (92.8\%) TNBC and 5/69 HER $2+(7.2 \%)$ cases were analyzed. After neoadjuvant therapy, pCR was achieved in 26 cases (37.7\%), pPR in 38 cases $(55.1 \%)$, and pNR in 5 cases (7.2\%) (Table 1 and Suppl. Table 1). The average LAPTM4B/CEN8q ratio was $\geq 2.0$ in only $6 / 69$ (8.6\%) cases with the highest ratio being 3.71 .

Considering the average $L A P T M 4 B$ copy number/cell in the group of patients receiving anthracycline-based neoadjuvant therapy, higher average $L A P T M 4 B$ gene copy number was observed in the pNR group compared to pCR group (4.1 \pm 1.1 vs. $2.6 \pm 0.1, p=0.029)$ (Figs. 1a, b, 2a).

We also compared average LAPTM $4 B$ gene copy numbers between patients who had no regression or who presented minimal response to anthracycline-based neoadjuvant therapy ( $>50 \%$ residual tumor remaining) (pNR + pPRiii) versus cases with pCR. Again, significantly higher average gene copy number was found in the group of patients with inferior response to anthracycline-based neoadjuvant therapy $(3.3 \pm 0.3$ vs. $2.6 \pm 0.1, p=0.035$, Fig. 2 c) .

The same is true for average CEN8q being significantly higher in the pNR and pNR + pPRiii groups compared to pCR group $(3.7 \pm 0.9$ vs. $2.2 \pm 0.1, p=0.048$ and $2.9 \pm 0.3$ vs. $2.2 \pm 0.1, p=0.040$ respectively).

In the non-anthracycline-treated group of patients, we observed pNR in a single case (Fig. 2b). Therefore, we compared $L A P T M 4 B$ gene copy number between $\mathrm{pNR}+$ pPRiii and pCR groups, resulting no significant differences $(p=0.360)$ (Fig. 2d).

Regarding average CEN8q copies, in the non-anthracycline-treated group of patients, no significant differences were observed between $\mathrm{pNR}+\mathrm{pPR}$ iii and $\mathrm{pCR}$ groups $(p=0.879)$.

In the second cohort, the mean age of the patients was 52 years (32-81). Of the 74 analyzed cases, $94.6 \%$ had invasive carcinoma of no special type and $5.4 \%$ of the cases presented other histological type $(n=1$ invasive lobular carcinoma, $n=1$ carcinoma anaplasticum, $n=1$ carcinoma medullare, $n=1$ apocrin carcinoma). By considering the breast carcinoma subtypes, 39/74 (52.7\%) were TNBC,
Fig. 1 LAPTM4B FISH images in anthracycline-treated cases. a Normal $L A P T M 4 B$ copy number in a core biopsy case diagnosed with pCR after neoadjuvant therapy and $\mathbf{b}$ higher average $L A P T M 4 B$ gene copy number in a case without any therapy response after neoadjuvant therapy; $\mathbf{c}$ a primary breast carcinoma case treated with adjuvant chemotherapy and presenting no distant organ metastasis during the follow-up period (d) and a primary breast carcinoma case who had higher average $L A P T M 4 B$ gene copies and recurrence in distant organs. LAPTM $4 B$ gene was labelled with red, whereas chromosome 8 centromeric region was stained with green fluorescent dye. Cell nuclei were counterstained with DAPI (blue). FISH photos were acquired using $63 \times$ objective
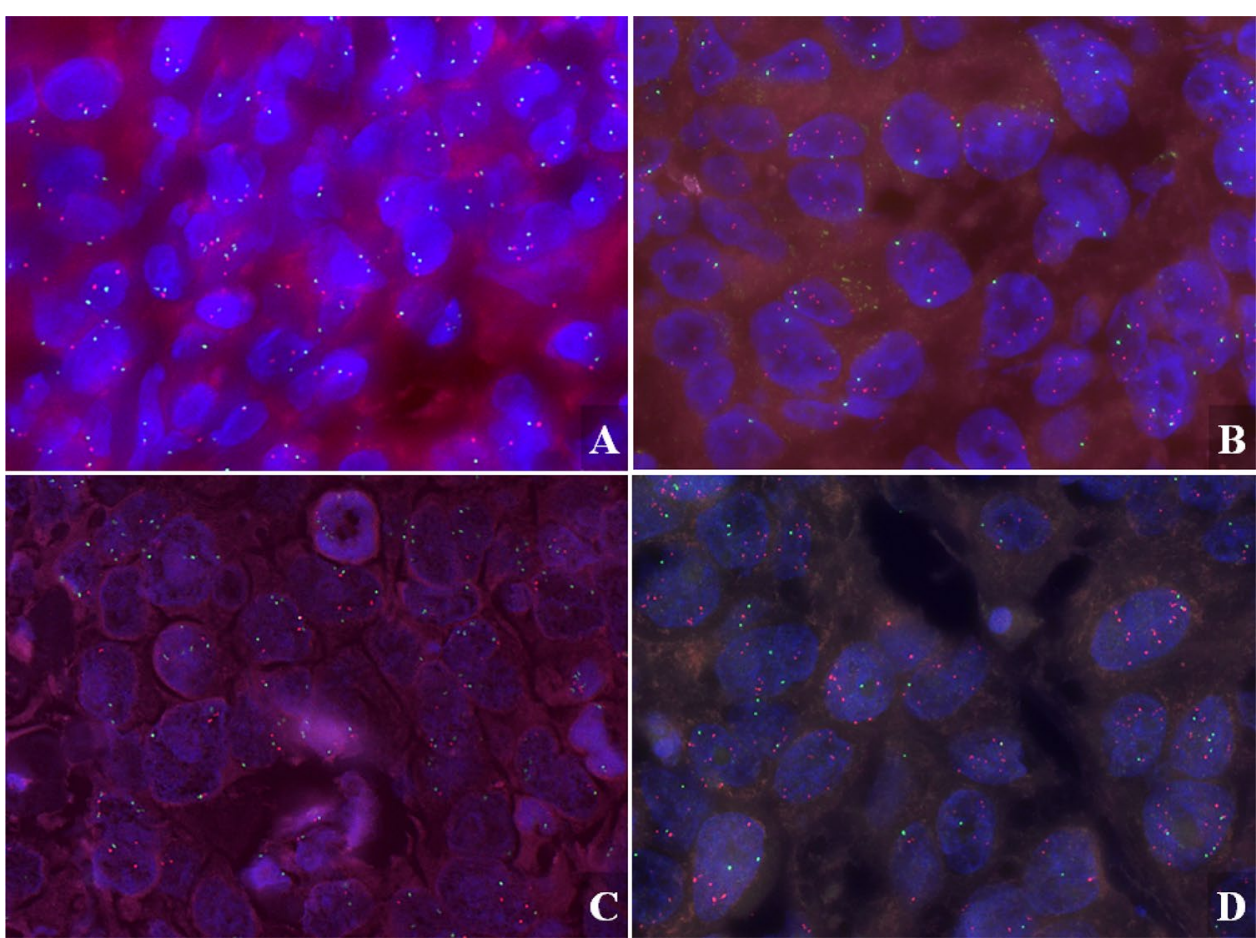

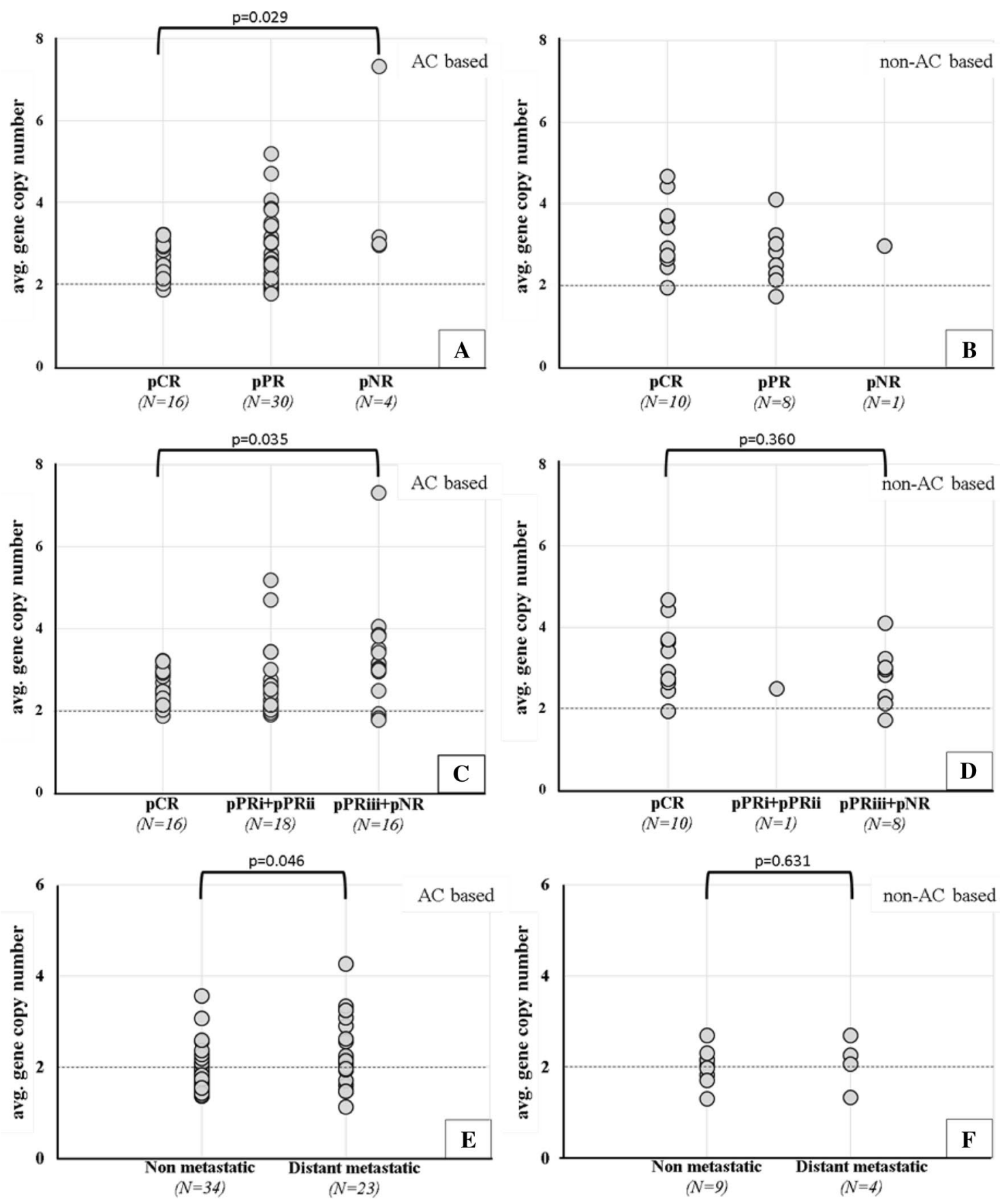

Fig. 2 Association between average LAPTM4B copy number and therapy response in the neoadjuvant (a-d) and in the adjuvant cohort (e, f). a In the anthracycline-treated cohort, significantly higher average $L A P T M 4 B$ gene copy number was observed in pNR group compared to $\mathrm{pCR}$ group $(p=0.029)$. b In the non-anthracyclinetreated group of patients, we observed pNR in a single case. c Significantly higher average $L A P T M 4 B$ gene copy number observed in $\mathrm{pNR}+\mathrm{pPR}$ iii group compared to $\mathrm{pCR}$ group $(p=0.035)$ in the

27/74 (36.5\%) HER2 +, and in 8/74 (10.8\%) cases, the HER2 status was unknown. During the follow-up period, distant metastases occurred in $30(40.5 \%)$ cases (Table 2 and Suppl. anthracycline-treated cohort, whereas, in the non-anthracyclinetreated cohort, (d) no significant differences were observed between the two groups. e Average gene copy number was significantly higher in metastatic cases, comparing to the non-metastatic ones in anthracycline-treated cohort $(p=0.046)$ and no significant differences in the non-anthracycline-treated cohort (f). A $p \leq 0.050$ was considered statistically significant using two-sided Mann-Whitney-Wilcoxon exact test

Table 2). $L A P T M 4 B / C E N 8 q$ ratio $\geq 2.0$ was observed in only $4 / 74$ (5.4\%) cases. Again considering the average $L A P T M 4 B$ gene copy number in the adjuvant anthracycline-treated 
patient cohort, the average $L A P T M 4 B$ gene copy number was higher in metastatic cases, compared to the non-metastatic ones $(2.2 \pm 0.2$ vs. $1.9 \pm 0.1, p=0.046$, Figs. $1 \mathrm{c}, \mathrm{d}$, $2 \mathrm{e})$. In patients treated with other than anthracycline chemotherapy, no significant differences were detected between metastatic vs. non-metastatic groups (Fig. 2f).

Regarding average CEN8q copies, no significant differences were observed between metastatic vs. non-metastatic groups neither in anthracycline-treated nor in non-anthracycline-treated patients.

Comparison of the two HR- subtypes (HER2+ and TNBC cases) showed no significant differences in the average $L A P T M 4 B$ gene copy number/cell $(p=0.328)$.

Kaplan-Meier curve estimation based on DMFS revealed that higher LAPTM4B copy number was an independent predictor for DMFS in the anthracycline-treated adjuvant cohort (Log-rank test, $p=0.037$ ). Cut-off value for poor prognosis was defined as follows: the ratio of amplified cell (LAPTM4B/CEN8q $\geq 2.0$ ) population is more than $15 \%$ and the average gene copy number is more than 2.5 per sample (Fig. 3). Based on these criteria, of the 22/57 patients treated with anthracycline-based adjuvant chemotherapy and diagnosed with distant metastases, $6 / 22$ cases presented higher LAPTM $4 B$ gene copy number, whereas, in $16 / 22$ cases, lower $L A P T M 4 B$ gene copy number was detected. Cox regression analysis was also performed, revealing association between increased $L A P T M 4 B$ gene copy number and DMFS $(p=0.044)$.

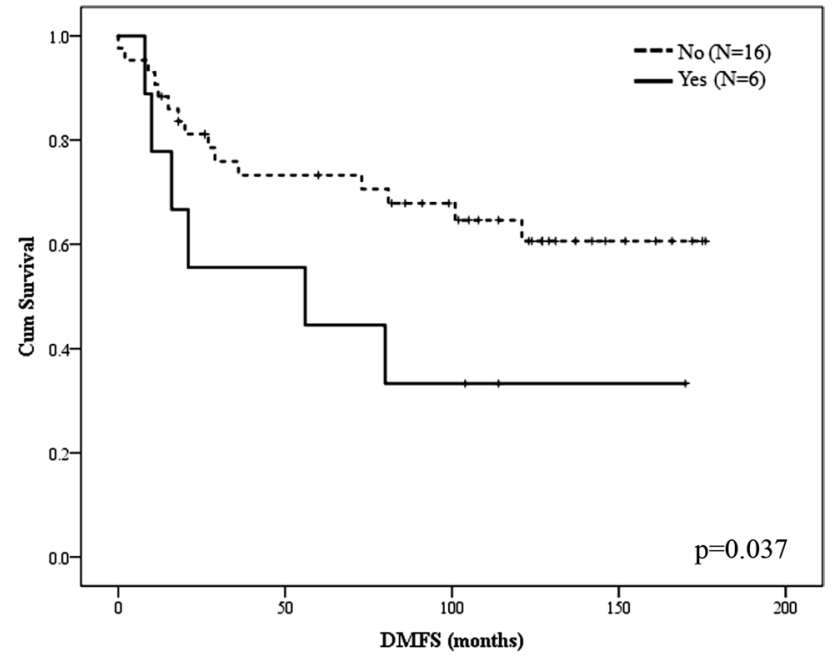

Fig. 3 Kaplan-Meier curve estimation of DMFS in the anthracycline (AC)-treated adjuvant cohort. Cut-off value for poor prognosis was defined as follows: the ratio of amplified cell (LAPTM4B/ CEN8q $\geq 2.0$ ) population is more than $15 \%$ and the average gene copy number is more than 2.5 per sample. Based on this criterion, $6 / 22$ cases presented higher $L A P T M 4 B$ gene copy number, whereas, in $16 / 22$ cases, lower LAPTM4B gene copy number was detected (logrank test, $p$ value was 0.037 )

\section{Discussion}

Anthracyclines are still the most widely used chemotherapeutic agents given as either adjuvant or neoadjuvant therapy $[11,12]$. Considering that approximately $30 \%$ of the early stage breast cancers progress to the metastatic stage, and the fact that the response rate to anthracycline or taxane-based chemotherapy ranges from 30 to $70 \%$, predictors of treatment efficacy to the various chemotherapeutic agents would have significant clinical importance $[1,3,13,14]$.

The potential role of LAPTM4B in tumor progression and chemotherapy resistance was first recognized about a decade ago. Kasper et al. [15] by analyzing different tumor types found that LAPTM4B was upregulated in $88 \%(23 / 26)$ of lung, in $67 \%(18 / 27)$ of colon carcinoma patients, and in the majority of endometrial (30/44), breast (27/53) and ovarian (11/16) carcinomas. They concluded that LAPTM4B have a dual functional involvement in tumor cell proliferation as well as in multidrug-resistance. Later, a significant functional association was found between lysosomal LAPTM4B overexpression and poor response to anthracycline chemotherapy in a neoadjuvant chemotherapy trial [5]. Although more and more new LAPTM4B mechanisms of action have been described, several unanswered questions have still remained.

One proposed mechanism of action by which LAPTM4B may confer anthracycline resistance is the cytosolic retention of the drug, thereby reducing the drug-induced DNA damage [16]. A different study proposed that the interaction of LAPTM4B-35 isoform with MDR 1 could result in increased drug efflux. In addition, the activation of the PI3K/AKT signaling pathway by LAPTM4B-35 was proposed as anti-apoptotic mechanism $[17,18]$. Li et al. have found that knockdown of LAPTM4B in MDA-MB-231 and BT549 cell lines has lead to elevated nuclear localization of doxorubicin [5]. Moreover, Li et al. found that LAPTM4B is required for lysosome homeostasis, acidification, and function. By limiting lysosomemediated cell death and promoting autophagy, the protein has a significant effect on cancer cell survival, including greater resistance to nutrient deprivation, hypoxia, or chemotherapy-induced genotoxic stress [9].

Based on the results obtained from the analysis of our neoadjuvant cohort treated with anthracycline-based chemotherapy, and documenting higher average $L A P T M 4 B$ copy number in the non-responder group and in $\mathrm{PPR}$ responders where $>50 \%$ of tumor cellularity remains evident, it seems reasonable to consider that LAPTM4B may contribute to chemoresistance against anthracyclines. In accordance with the results of Li et al. [5], we found that LAPTM4B alterations were not associated with treatment response 
in the non-anthracycline-treated group of patients. However, the association of LAPTM4B overexpression with tumor progression is more speculative, and there is only a limited amount of supporting information in this regard $[17,19,20]$. In the present series of HR- breast carcinomas, we observed that, in the anthracycline-treated adjuvant cohort, the average gene copy number was higher in primary breast carcinomas where distant metastases were diagnosed during the follow-up period compared to the non-metastatic ones. It is questionable whether the association of $L A P T M 4 B$ with poor prognosis is a consequence of anthracycline resistance or, as it is presented by Xiao M. et al., LAPTM4B has other mechanisms of action to promote cell proliferation, migration, invasion, leading to simultaneous upregulation of $\mathrm{N}$-cadherin, vimentin, and downregulation of E-cadherin in T47D cells [20].

$\mathrm{Li}$ et al. found that elevated level of LAPTM4B and YWHAZ (another gene localized on 8q22) mRNAs was associated with shorter DMFS in women treated with adjuvant anthracycline chemotherapy. They also questioned whether this is a prognostic effect or a role of this two genes in chemotherapy resistance [5]. In other tumor types, such as hepatocellular- and ovarian carcinomas, the prognostic role of LAPTM4B was documented [21, 22]. Although Xiao $\mathrm{M}$ et al. showed that high LAPTM4B expression level is an independent predictor of axillary lymph node metastasis in breast carcinoma patients, unfortunately, no data were presented related to different breast cancer subtypes. In our study, only HR - breast carcinomas were analyzed and we found no significant difference of LAPTM4B copy number between HER 2 + and TNBC subtypes. However, further analysis may be needed using higher number of cases.

The prognostic value of higher average CEN8q or chromosome 8 polysomy in breast carcinomas is not clear. We have found significantly higher average CEN8q copies in the group of patients with inferior response to anthracyclinebased neoadjuvant therapy. Anna Batistatou et al. in 2017 have found that polysomy-8 was present in 39\% HER2positive tumors and in 30.2\% HER2-negative tumors. They also showed that MYC gene amplification in the presence of chromosome- 8 instability has distinct effects on patient outcome compared with MYC amplification with intact CEN8 [23].

In summary, the results of our study confirm the possible role of $L A P T M 4 B$ gene in anthracycline resistance in HR- breast carcinomas. Alternative treatment modalities without anthracycline should be considered for those patients whose cancer harbors extra copies LAPTM4B.

\section{Limitations of the study}

Our results should be interpreted cautiously, since our patient cohort had relatively few cases in the pNR group.
Cases were retrospectively selected from prospectively maintained databases.

Acknowledgements We would like to thank Erzsébet Kovács for technical assistance and Stefan Vari-Kakas for manuscript revision.

Funding This study was funded by seven grants: (1) New National Excellence Program (ÚNKP-17-4-II-SE-65); (2) New National Excellence Program (ÚNKP-17-4-III-SE-71); (3) National Talent Program (NTP-NFTÖ-17-B-0308) of the Ministry of Human Capacities; (4) NVKP_16-1-2016-0004; (5) STIA 19/2017, 6800313113, 68003F0043; (6) The Research and Technology Innovation Fund (KTIA_NAP_132014-0021 to Z.S.). (7) Breast Cancer Research Foundation (Z.S.).

\section{Compliance with ethical standards}

Conflict of interest The authors declare that they have no conflict of interest. Orsolya Rusz declares that she has no conflict of interest. Orsolya Papp declares that she has no conflict of interest. Laura Vízkeleti declares that she has no conflict of interest. Béla Ákos Molnár declares that he has no conflict of interest. Kristóf Csaba Bende declares that he has no conflict of interest. Gábor Lotz declares that he has no conflict of interest. Balázs Ács declares that he has no conflict of interest. Zsuzsanna Kahán declares that she has no conflict of interest. Tamás Székely declares that he has no conflict of interest. Ágnes Báthori declares that she has no conflict of interest. Csilla Szundi declares that she has no conflict of interest. Janina Kulka declares that she has no conflict of interest. Zoltán Szállási declares that he has no conflict of interest. Anna-Mária Tőkés declares that she has no conflict of interest.

Ethical approval The study was ethically approved by the Semmelweis University Institutional Review Board (SE-TUKEB 120/2013). All procedures performed in studies involving human participants were in accordance with the ethical standards of the institutional and/ or national research committee and with the 1964 Helsinki declaration and its later amendments or comparable ethical standards.

Informed consent The breast carcinoma cases were retrospectively selected from prospectively maintained databases (Primary breast carcinoma cases were diagnosed between 1999 and 2016), and accordingly, informed consent was not obtained from all individual participants included in the study.

\section{References}

1. Gralow JR (2005) Optimizing the treatment of metastatic breast cancer. Breast Cancer Res Treat 89(Suppl 1):S9-S15. https://doi. org/10.1007/s10549-005-0143-z

2. Haibe-Kains B, Desmedt C, Di Leo A, Azambuja E, Larsimont D, Selleslags J, Delaloge S, Duhem C, Kains JP, Carly B, Maerevoet M, Vindevoghel A, Rouas G, Lallemand F, Durbecq V, Cardoso F, Salgado R, Rovere R, Bontempi G, Michiels S, Buyse M, Nogaret JM, Qi Y, Symmans F, Pusztai L, D’Hondt V, Piccart-Gebhart M, Sotiriou C (2013) Genome-wide gene expression profiling to predict resistance to anthracyclines in breast cancer patients. Genom Data 1:7-10. https://doi.org/10.1016/j.gdata.2013.09.001

3. Desmedt C, Di Leo A, de Azambuja E, Larsimont D, HaibeKains B, Selleslags J, Delaloge S, Duhem C, Kains JP, Carly B, Maerevoet M, Vindevoghel A, Rouas G, Lallemand F, Durbecq V, Cardoso F, Salgado R, Rovere R, Bontempi G, Michiels S, Buyse M, Nogaret JM, Qi Y, Symmans F, Pusztai L, D'Hondt V, Piccart-Gebhart M, Sotiriou C (2011) Multifactorial approach to 
predicting resistance to anthracyclines. J Clin Oncol 29:15781586. https://doi.org/10.1200/JCO.2010.31.2231

4. Mukherjee A, Shehata M, Moseley P, Rakha E, Ellis I, Chan $S$ (2010) Topo2alpha protein expression predicts response to anthracycline combination neo-adjuvant chemotherapy in locally advanced primary breast cancer. Br J Cancer 103:1794-1800. https://doi.org/10.1038/sj.bjc.6605960

5. Li Y, Zou L, Li Q, Haibe-Kains B, Tian R, Desmedt C, Sotiriou C, Szallasi Z, Iglehart JD, Richardson AL, Wang ZC (2010) Amplification of LAPTM4B and YWHAZ contributes to chemotherapy resistance and recurrence of breast cancer. Nat Med 16:214-218. https://doi.org/10.1038/nm.2090

6. Skovsgaard T, Nissen NI (1982) Membrane transport of anthracyclines. Pharmacol Ther 18:293-311

7. Kiyomiya K, Matsuo S, Kurebe M (2001) Mechanism of specific nuclear transport of adriamycin: the mode of nuclear translocation of adriamycin-proteasome complex. Cancer Res 61:2467-2471

8. Larsen AK, Escargueil AE, Skladanowski A (2000) Resistance mechanisms associated with altered intracellular distribution of anticancer agents. Pharmacol Ther 85:217-229

9. Li Y, Zhang Q, Tian R, Wang Q, Zhao JJ, Iglehart JD, Wang ZC, Richardson AL (2011) Lysosomal transmembrane protein LAPTM4B promotes autophagy and tolerance to metabolic stress in cancer cells. Cancer Res 71:7481-7489. https://doi. org/10.1158/0008-5472.CAN-11-0940

10. Pinder SE, Provenzano E, Earl H, Ellis IO (2007) Laboratory handling and histology reporting of breast specimens from patients who have received neoadjuvant chemotherapy. Histopathology 50:409-417. https://doi.org/10.1111/j.1365-2559.2006.02419.x

11. Tang Y, Soroush F, Tong Z, Kiani MF, Wang B (2017) Targeted multidrug delivery system to overcome chemoresistance in breast cancer. Int J Nanomedicine 12:671-681. https://doi.org/10.2147/ IJN.S124770

12. Vaz-Luis I, Burstein HJ (2016) Optimizing adjuvant chemotherapy and surgery for early- and late-stage breast cancer. JAMA Oncol 2:1399-1400. https://doi.org/10.1001/jamaoncol.2016.3631

13. Molnar IA, Molnar BA, Vizkeleti L, Fekete K, Tamas J, Deak P, Szundi C, Szekely B, Moldvay J, Vari-Kakas S, Szasz MA, Acs B, Kulka J, Tokes AM (2017) Breast carcinoma subtypes show different patterns of metastatic behavior. Virchows Arch 470:275-283. https://doi.org/10.1007/s00428-017-2065-7

14. O'Shaughnessy J (2005) Extending survival with chemotherapy in metastatic breast cancer. Oncologist 10 Suppl 3:20-29. https:// doi.org/10.1634/theoncologist.10-90003-20

15. Kasper G, Vogel A, Klaman I, Grone J, Petersen I, Weber B, Castanos-Velez E, Staub E, Mennerich D (2005) The human LAPTM4b transcript is upregulated in various types of solid tumours and seems to play a dual functional role during tumour progression. Cancer Lett 224:93-103. https://doi.org/10.1016/j. canlet.2004.10.004

16. Perreard L, Fan C, Quackenbush JF, Mullins M, Gauthier NP, Nelson E, Mone M, Hansen H, Buys SS, Rasmussen K, Orrico AR, Dreher D, Walters R, Parker J, Hu Z, He X, Palazzo JP, Olopade OI, Szabo A, Perou CM, Bernard PS (2006) Classification and risk stratification of invasive breast carcinomas using a real-time quantitative RT-PCR assay. Breast Cancer Res 8:R23. https://doi. org/10.1186/bcr1399

17. de Ronde JJ, Lips EH, Mulder L, Vincent AD, Wesseling J, Nieuwland M, Kerkhoven R, Vrancken Peeters MJ, Sonke GS, Rodenhuis S, Wessels LF (2013) SERPINA6, BEX1, AGTR1, SLC26A3, and LAPTM4B are markers of resistance to neoadjuvant chemotherapy in HER2-negative breast cancer. Breast Cancer Res Treat 137:213-223. https://doi.org/10.1007/s1054 9-012-2340-x

18. Venet D, Dumont JE, Detours V (2011) Most random gene expression signatures are significantly associated with breast cancer outcome. PLoS Comput Biol 7:e1002240. https://doi.org/10.1371/ journal.pcbi.1002240

19. Xiao M, Jia S, Wang H, Wang J, Huang Y, Li Z (2013) Overexpression of LAPTM4B: an independent prognostic marker in breast cancer. J Cancer Res Clin Oncol 139:661-667. https://doi. org/10.1007/s00432-012-1368-y

20. Xiao M, Yang S, Meng F, Qin Y, Yang Y, Jia S, Cai X, Li C, Huang Y, Ning X (2017) LAPTM4B predicts axillary lymph node metastasis in breast cancer and promotes breast cancer cell aggressiveness in vitro cell. Physiol Biochem 41:1072-1082. https://doi. org/10.1159/000464115

21. Yang H, Xiong F, Wei X, Yang Y, McNutt MA, Zhou R (2010) Overexpression of LAPTM4B-35 promotes growth and metastasis of hepatocellular carcinoma in vitro and in vivo. Cancer Lett 294:236-244. https://doi.org/10.1016/j.canlet.2010.02.006

22. Yin M, Lou C, Zhang W, Meng F, Zhang H, Ning X, Zhou R, Dong X, Lou G (2012) LAPTM4B overexpression is a novel independent prognostic marker for metastatic ovarian tumors. Int J Gynecol Cancer 22:54-62. https://doi.org/10.1097/IGC.0b013 e318234f9ac

23. Batistatou A, Kotoula V, Bobos M, Kouvatseas G, Zagouri F, Tsolaki E, Gogas H, Koutras A, Pentheroudakis G, Timotheadou E, Pervana S, Goussia A, Petraki K, Sotiropoulou M, Koletsa T, Razis E, Kosmidis P, Aravantinos G, Papadimitriou C, Pectasides D, Fountzilas G (2017) Correlation of MYC gene and protein status with breast cancer subtypes and outcome of patients treated with anthracycline-based adjuvant chemotherapy. Pooled analysis of 2 Hellenic Cooperative Group Phase III Trials. Clin Breast Cancer 18:53-62.e3. https://doi.org/10.1016/j.clbc.2017.07.004

\section{Affiliations}

\section{Orsolya Rusz ${ }^{1}$ - Orsolya Papp ${ }^{2}$. Laura Vízkeleti ${ }^{2,3}$ - Béla Ákos Molnár ${ }^{4} \cdot$ Kristóf Csaba Bende $^{2} \cdot$ Gábor Lotz $^{2}$. Balázs Ács ${ }^{2}$. Zsuzsanna Kahán ${ }^{1}$. Tamás Székely ${ }^{2}$. Ágnes Báthori ${ }^{5}$ · Csilla Szundi ${ }^{2}$. Janina Kulka ${ }^{2}$. Zoltán Szállási ${ }^{2,3,6,7}$. Anna-Mária Tökés ${ }^{2}$}

\author{
Orsolya Rusz \\ rusz.orsolya@med.u-szeged.hu \\ Orsolya Papp \\ papporsolya91@gmail.com \\ Laura Vízkeleti \\ laura.vizkeleti@gmail.com
}

Béla Ákos Molnár

molnar.bela.akos@gmail.com

Kristóf Csaba Bende

kristof.bende@gmail.com

Gábor Lotz

lotz.gabor@med.semmelweis-univ.hu 
Balázs Ács

acs.balazs.se@gmail.com

Zsuzsanna Kahán

kahan.zsuzsanna@med.u-szeged.hu

Tamás Székely

drtamasszekely@gmail.com

Ágnes Báthori

bathori.agnes87@gmail.com

Csilla Szundi

szundi.csilla@gmail.com

Janina Kulka

janinakulka@gmail.com

Zoltán Szállási

zoltan.szallasi@childrens.harvard.edu

1 Department of Oncotherapy, University of Szeged, Korányi fasor 12, Szeged 6720, Hungary
2 2nd Department of Pathology, Semmelweis University, Üllői út 93, Budapest 1091, Hungary

3 MTA-SE-NAP B Brain Metastasis Research Group, 2nd Department of Pathology, Semmelweis University, Budapest, Hungary

4 1st Department of Surgery, Semmelweis University, Üllői út 78, Budapest 1082, Hungary

5 Department of Pathology, University of Szeged, Állomás u. 2, Szeged 6725, Hungary

6 Department of Bio and Health Informatics, Technical University of Denmark, Kemitorvet 208, 2800 Lyngby, Denmark

7 Computational Health Informatics Program, Boston Children's Hospital, Harvard Medical School, Harvard University, 300 Longwood Avenue, Boston, MA 02115, USA 